\title{
Anabases
}

ANABASES Traditions et réceptions de l'Antiquité

$23 \mid 2016$

Varia

\section{Anthony ANDURAND, Le Mythe grec allemand. Histoire d'une affinité élective}

\section{Lucien Calvié}

\section{OpenEdition}

Journals

Édition électronique

URL : http://journals.openedition.org/anabases/5678

DOI : 10.4000/anabases.5678

ISSN : 2256-9421

\section{Éditeur}

E.R.A.S.M.E.

\section{Édition imprimée}

Date de publication : 2 mai 2016

Pagination : 299-300

ISSN : 1774-4296

\section{Référence électronique}

Lucien Calvié, «Anthony andurand, Le Mythe grec allemand. Histoire d'une affinité élective », Anabases [En ligne], 23 | 2016, mis en ligne le 02 mai 2016, consulté le 22 septembre 2020. URL : http:// journals.openedition.org/anabases/5678; DOI : https://doi.org/10.4000/anabases.5678

Ce document a été généré automatiquement le 22 septembre 2020.

(c) Anabases 


\title{
Anthony ANDURAND, Le Mythe grec allemand. Histoire d'une affinité élective
}

\author{
Lucien Calvié
}

\section{RÉFÉRENCE}

Anthony ANDURAND, Le Mythe grec allemand. Histoire d'une affinité élective

Rennes, Presses universitaires de Rennes, 2013, $404 \mathrm{p}$.

22 euros / ISBN 978-2-7535-2879-6

1 En 1967, un de mes condisciples à l'École normale supérieure, helléniste me sachant détaché comme lecteur dans une université allemande, me serinait par lettre : " Achète-moi des Teubner ! » Lorsque je lui demandais lesquels, il me répondait : « N'importe, tous sont bons!" Il trouvait les éditions de la Bibliotheca Scriptorum Graecorum et Romanorum supérieures à celles de la collection Budé : prestige persistant de la philologie allemande. De cette philologie, il est question dans ce livre issu d'une thèse soutenue en 2011 à Toulouse. Et, plus largement, d'une science allemande de l'Antiquité classique (Altertumswissenschaft), limitée par son " héros fondateur », F.A. Wolf, dès 1807, à la Grèce et à Rome, à l'exclusion de l'Orient.

Mais ce n'est pas seulement de cette science de l'Antiquité qu'il est question ici. Car une science, même prestigieuse, ne fonde pas un mythe. Ce mot imprécis parait enrichir la réflexion de celui qui l'emploie, lui donner de la profondeur. Parler du mythe de la Révolution, de Napoléon ou de de Gaulle semble plus consistant que l'examen de leur image, de leur représentation - littéraire, picturale ou cinématographique - ou de l'idée que les uns ou les autres, à tel ou tel moment, s'en font, et de son utilisation au fil du débat politique. En 1987, pourtant, dans une préface à une réédition de son livre de 1962, Les origines de la pensée grecque, J.-P. Vernant soulignait que les anthropologues « nous mettent en garde contre la tentation d'ériger le mythe en une sorte de réalité 
mentale inscrite dans la nature humaine ", avant d'ajouter : "Le mot mythe nous vient des Grecs. Mais il n'avait pas [...] aux temps archaïques le sens que nous lui donnons aujourd'hui. Muthos veut dire "parole", "récit". Il ne s'oppose pas [...] à logos, dont le sens premier est également "parole, discours", avant de désigner l'intelligence et la raison. C'est seulement dans le cadre de l'exposé philosophique ou de l'enquête historique qu'à partir du v siècle [av. J.-C.] muthos, mis en opposition avec logos, pourra se charger d'une nuance péjorative [...]. »

Or, c'est bien d'un mythe - le mythe grec allemand, ou le mythe grec des Allemands, ou encore le mythe d'une Allemagne " grecque » faisant revivre le " miracle » de la Grèce ancienne - que traite Andurand, qui utilise donc judicieusement ici le terme de " mythe ", souvent trop vague et extensif.

Ce mythe d'une "affinité élective " germano-grecque et d'une Allemagne consubstantiellement grecque, Andurand en retrace les évolutions par ordre chronologique, les coupures qu'il propose étant celles de l'histoire de l'Allemagne et de l'Europe. Partant, dans une première partie, de la deuxième moitié du XVIII ${ }^{e}$ siècle et de la période révolutionnaire et napoléonienne (1755-1815), autour de Winckelmann, puis W. von Humboldt - avec l'idéal d'éducation (Bildung) de l'individu et de la nation -, et Wolf, il en vient, dans la deuxième partie, au XIX ${ }^{e}$ siècle (1815-1890), autour de la construction d'une unité nationale allemande achevée avec la guerre de 1870-1871 contre la France, l'historien Droysen établissant en quelque sorte par anticipation, dès 1833, un parallèle entre une Macédoine unifiant les Grecs et une Prusse destinée à le faire pour les Allemands, sans qu'un mythe prusso-macédonien se substitue au mythe germano-grec, sans doute à cause du soupçon de « barbarie " pesant sur la Macédoine. Après la «trop belle " victoire de 1871, Nietzsche et Burckhardt introduisent une dimension nouvelle - et "décadente ", avec ses conséquences jusqu'au nazisme, oserai-je ajouter - dans l'hellénisme allemand, celle du pessimisme, opposé à un bonheur grec ne faisant qu'un avec la liberté et la beauté.

5 La troisième partie (1890-1945) traite d'abord de l'Allemagne impériale et impérialiste de Guillaume II, avec Wilamowitz et la modernisation du lycée classique (Gymnasium) humboldtien. Après les hésitations de l'intermède républicain (1919-1933), le III ${ }^{e}$ Reich emporte le mythe grec des Allemands vers les délires du mythe aryen et d'une statuaire grecque confondue avec la supposée beauté du corps héroïque et nordique. Le critique marxiste Lukacs, Andurand aurait pu le rappeler, avait signalé la "bestialisation hystérique de l'Antiquité ", bien avant le nazisme, chez Nietzsche et dans l'impérialisme wilhelminien.

6 Deux remarques encore. À propos de Fichte et des Discours à la nation allemande, Andurand n'évoque pas ce que son éloge du caractère supposé originel et pur, comme pour le grec, de la langue allemande, mais aussi, par extension, de la " race » allemande, par opposition à des langues romanes issues du latin par " dégénérescence » et à des " races » latines nées d'un métissage lui aussi " dégénéré » d'indigènes et de Latins, a de racialiste, voire de raciste. Et il semble ignorer que la même opposition, mais seulement entre langues "pures » et "dégénérées ", se retrouve, au même moment, chez le très « humaniste » Humboldt. En fait, ce thème de l'opposition entre ce qui est supposé romain, ou français, et ce qui est supposé grec, ou germanique, est ancien et général. Sans remonter jusqu'à la Germanie de Tacite, on pense à la volonté luthérienne de rupture avec une Rome sous tous ses aspects (Los von Rom !), mais aussi, chez Fichte et ses contemporains (F. Schlegel, F.A.Wolf), à l'opposition entre une 
France "servilement " romaine, mécanique, administrative (l'État constituant sa nation) et sans âme et une Allemagne " librement " grecque, organique, spontanée (la nation et la langue construisant leur État) et portée à l'idéal. Étrange retournement d'une liberté pourtant largement « portée " par la France depuis 1789.

7 Autre remarque : si, lorsque les savants, philosophes, hommes de lettres et hommes d'État allemands, du xviII ${ }^{e}$ au $x^{e}$ siècle, parlent de la Grèce, c'est en fait de leur Allemagne réelle ou fantasmée qu'il s'agit, la remarque ne vaut-elle pas aussi pour d'autres pays ? En France, par exemple, dans le Démosthène publié par Clemenceau, le " père la Victoire » de 1918, en 1925 dans L'Illustration, puis en 1926 comme livre, n'estce pas, à travers Athènes trop faible face à Philippe de Macédoine, de la France d'après 1918 qu'il s'agit, acceptant trop facilement le démantèlement du traité de Versailles au bénéfice de l'Allemagne, s'abandonnant aux délices insouciantes d'une paix illusoire et s'exposant au retour offensif de la " barbarie " germanique ? Le lucide, vigilant et inflexible Démosthène de ce texte, n'est-ce pas Clemenceau lui-même, déjà conscient, bien avant 1940, que la période 1914-1945 ne constituera qu'une seule "Guerre de Trente ans du xx siècle »?

\section{AUTEURS}

\section{LUCIEN CALVIÉ}

Université Toulouse-Jean Jaurès (UT2J)

claude.calvie@orange.fr 